\title{
Bullying, Peer Victimization, and Child and Adolescent Health: An Introduction to the Special Issue
}

\author{
Jun Sung Hong ${ }^{1,2} \cdot$ Dorothy L. Espelage ${ }^{3}$. Chad A. Rose ${ }^{4}$
}

Published online: 29 June 2019

(c) Springer Science+Business Media, LLC, part of Springer Nature 2019

\begin{abstract}
Significant health problems of adolescents involved in bullying has been documented in the research literature. Research consistently reports that youth who are involved in bullying are at a significant risk of health problems (e.g., depression, anxiety, sleeplessness). Likewise, those with health problems are at an increased odds of bullying and peer victimization. The Special Issue, "Bullying, Peer Victimization, and Child and Adolescent Health", of the Journal of Child and Family Studies brings together scholars around the world to disseminate their research findings on the relevance of bullying and peer victimization in children and adolescent's health and mental health.
\end{abstract}

Keywords Adolescents $\cdot$ Bullying $\cdot$ Health $\cdot$ Mental health $\cdot$ Peer victimization $\cdot$ Youth

Bullying is widely acknowledged as a serious public health concern, which affects children and adolescents from across the globe. According to the National Academies of Science, Engineering, and Medicine (2016), "bullying behavior is a major public health problem that demands the concerted and coordinated time and attention of parents, educators and school administrators, health care providers, policy makers, families and other concerned with the care of children" and there are "biological and psychological consequences of peer victimization. Bullying is a multifaceted form of mistreatment, mostly seen in schools and the workplace. It is characterized by the repeated exposure of one person to physical and/or emotional aggression including teasing, name calling, mockery, threats, harassment, taunting, hazing, social exclusion or rumours" (Srabstein and Leventhal 2010, p. 403). Health is defined by the World Health Organization as "a state of complete physical, mental and

Jun Sung Hong

fl4684@wayne.edu

1 School of Social Work, Wayne State University, Detroit, MI, USA

2 Department of Social Welfare, Sungkyunkwan University, Seoul, Korea

3 Department of Psychology, University of Florida, Gainesville, FL, USA

4 Department of Special Education, College of Education, University of Missouri, Columbia, MO, USA social well-being and not merely the absence of disease or infirmity" (Larson 1996, p. 181).

A growing body of research worldwide has documented the range of significant health problems of individuals involved in bullying whether as bystanders, bullies and/or victims. More specifically, a large body of the research literature has found that children who are identified as bullies, victims, or bully/victims (i.e., victims who become bullies) are at an increased odds of developing health problems, including depression, anxiety, sleeplessness, poor eating habits, and suicidal behavior (Arseneault et al. 2010; Cooper et al. 2004; Copeland et al. 2015; Holt et al. 2015). The health consequences of bullying can also extend to adulthood, as demonstrated in several longitudinal studies (Takizawa et al. 2015; Wolke et al. 2013). Similarly, children with health problems, such as asthma, hearing/visual impairments, obesity, eating disorders, cerebral palsy, etc. are at an elevated risk of bullying and peer victimization in school (Gibson-Young et al. 2014; Griffiths et al. 2006; Hadjikakou and Panayiotis 2012; Lindsay and McPherson 2012). The medical symptoms and the resulting physiological changes associated with bullying have mobilized public health officials and other health care professionals to address children's bullying.

The Special Issue, "Bullying, Peer Victimization, and Child and Adolescent Health", of the Journal of Child and Family Studies brings together scholars from around the world to provide a global discourse on the relevance of 
bullying and peer victimization in children and adolescent's health and mental health.

Attar-Schwartz et al. (2019) explore whether victimization mediated the association between classmates' support and internalizing and externalizing behaviors from a sample of 243 Canadian 7th-graders. Classmates' support was found to predict internalizing behaviors among females. Although classmates' support was not directly related to externalizing behavior, parental support predicted externalizing behavior. Youth violence was found to mediate the association between classmates' support and externalizing behavior. Overall, the study findings suggest that both peer support and parental support are important protective factors.

Baier et al. (2019) explore whether face-to-face bullying, cyberbullying, and teachers' bullying were associated with adolescent mental health and whether there were differences. The study consisted of a sample of 10,638 German 9th-graders. Their findings indicated that psychological cyberbullying had the strongest association with mental health problems for both genders relative to other forms of bullying. Relational bullying by classmates and by teachers was also positively associated with mental health problems. Significant association between sexual cyberbullying and mental health was found among girls, although physical bullying was not related to mental health problems.

Baldry et al. (2019) explore the association between post-traumatic stress symptoms and youth's involvement in bullying and cyberbullying based on different bullying roles. The sample comprised 5058 Italian students (aged 11-18 years) in secondary school. Results suggest that gender differences in post-traumatic stress symptoms and their roles in bullying and cyberbullying involvement. For school bullying, higher symptoms of stress were reported by youth identified as bully/victims and bullies-only, and girls showed higher symptoms. With regards to cyberbullying, youth identified as bully/victims and victims-only reported higher post-traumatic stress symptoms than bullies-only and uninvolved youth. Both school bullying and cyberbullying were positively associated with concurrent post-traumatic stress symptoms, which differentially affected adolescents according to their bullying involvement.

Davis et al. (2019) explore longitudinal reciprocal associations among bully victimization, depressive symptoms, and school belonging in a sample of 2177 middle school students (ages 11 to 15 ) in the U.S. Their findings suggested the importance of support for both symptom-driven and interpersonal risk models. The study also found a buffering effect between victimization and depressive symptoms of school belonging for females only. Moreover, the study findings also indicated that school belonging mitigated long-term problems that were related to bully victimization via reductions in depressive symptoms.
In a qualitative study, deLara (2009) explores the aftermath of childhood bullying for young adults with regards to their health, mental health, and relationship problems from a sample of 72 university students in the U.S. (18 to 29 years of age). The study results suggested a need for further research on childhood bullying and how it may affect later adolescent and young adult development.

DePaolis and Williford (2019) explore from a sample of U.S. elementary school students (660 and 960 3rd and 5th graders) change in cyberbullying victimization across time and how such change might influence their later health outcomes. Results indicated no consistent pattern of growth in victimization, although initial levels of cyberbullying victimization were significantly different from zero, which suggested that a notable number of the students reported cyberbullying victimization at baseline. Moreover, initial levels of cyberbullying victimization were associated with later health outcomes.

Duru et al. (2019) explore from a sample of 1993 Turkish high school students whether self-esteem mediates the associations among relational violence, depression, and anxiety and whether social support moderates these associations. The relationship between violence and social support was found to be directly and interactively associated with self-esteem. Self-esteem was found to mediate the associations among relational violence, depression, and anxiety. The findings also suggested that depending on the level of social support, the indirect effect of relational violence on depressive symptoms and anxiety through selfesteem might vary.

Evans et al. (2019) explore how cumulative experiences as a bullying victim and perpetrator over five years and cumulative bystander behavior over two years are linked to youth's aggression, internalizing problems, academic achievement, self-esteem, and future optimism. Sample for the study consisted of over 8000 middle- and high-school students from the Rural Adaptation Project in North Carolina to. Their findings suggested that cumulative peer victimization was significantly and positively related to aggression and internalizing problems and was negatively related to self-esteem and future optimism. Cumulative bullying perpetration was found to be positively related to aggression and negatively related to future optimism. Negative bystander behavior was found to be positively related to aggression and internalizing problems and negatively related to academic achievement and future optimism. On the other hand, prosocial bystander behavior was found to be positively related to internalizing problems, academic achievement, self-esteem, and future optimism.

Fogleman et al. (2019) explore a proposed model with a sample of 210 children (133 with ADHD, 77 without ADHD) in which ADHD was directly and indirectly associated with peer victimization through emotion regulation. 
In addition, emotion regulation was a predictor of peer victimization above and beyond the effects of ADHD. The study found that emotion regulation was directly associated with peer victimization for both children with and without ADHD. Also, the study found that ADHD was associated with peer victimization through emotion regulation.

Hatchel et al. (2019) explore a proposed model. Using a statewide sample of LGBTQ adolescents in the U.S. $(N=$ 4867 high school students in 20 schools), they proposed that peer victimization, drug use, depressive symptoms, and help-seeking beliefs were predictors of suicidal ideation and attempts. Their findings indicated that intentions to use drugs, peer victimization, and elevated depressive symptoms were positively associated with suicidal ideation and attempts. Moreover, help-seeking beliefs were associated with suicidal attempts but not ideation, while the interaction of help-seeking beliefs and depressive symptoms was significant in suicidal ideation.

Hatchel, Subrahmanyam, and Negriff's (2019) retrospective study explores the associations among online and offline peer victimization, internalizing problems, and offline and online social support. The study comprised a sample of 416 U.S. participants, aged 18-24. Findings suggest that retrospective reports of peer victimization and social support were predictors of internalizing problems. More specifically, peer victimization was a stronger predictor of depressive symptoms than social anxiety. On the other hand, offline social support negatively predicted internalizing problems, but online support was not significant. Social support was found to buffer the link between peer victimization and social anxiety.

Hatchel, Valido, De Pedro, Huang, and Espelage's (2019) study, which consists of with an ethnically diverse sample of transgender adolescents in the U.S. $(N=4778)$, explores the associations among peer victimization, school belonging, and mental health. Their findings indicated that a high number of transgender youth reported being exposed to victimization and that victimization was a significant predictor of mental health problems, such as suicidal ideation. Moreover, peer victimization was found to be significantly related to diminished school belonging; however, school belonging was found to be associated with better mental health and mediated the link between victimization and mental health problems.

Herkama et al. (2019) propose a hypothesis, which purports that the association between peer victimization and depression is partly mediated by difficulty in sleeping. Sample for the study included 1717 Finnish students from 20 school districts. Their results indicated that sleeping difficulties is attributed to peer victimization.

Hsieh et al. (2019) explore whether emotional intelligence and social intelligence moderate the association between peer victimization and internet addiction. They also examine whether they moderated the relationship between peer victimization and psychological distress in a national proportionately stratified random sample of 6233 Taiwanese 4th-graders. Their results suggest that students who had experienced more peer victimization reported higher risk of internet addiction and psychological distress. Although emotional intelligence was negatively related to internet addiction, it did not moderate the association between peer victimization and internet addiction. Social awareness was negatively associated with internet addiction, but amplified the negative effect of peer victimization on internet addiction. Both emotional intelligence and social information processing were negatively associated with psychological distress and moderated the negative effect of peer victimization on mental health.

Huitsing et al. (2019) explore the "healthy context paradox" which is conceptualized as potentially negative outcomes of school anti-bullying norms on victims' psychological and school adjustment. Sample for the study consists of 4356 Dutch students from 245 classrooms in 99 school districts. Results of the study highlight the importance of considering the interaction between individual and the environment in understanding the consequences of bullying victimization. The study underscores the importance of adults and classmates in providing support for the victims of bullying in schools that have antibullying interventions.

Jennings et al. (2019) explore the association between bullying victimization and adolescent physical health. Sample for the study is comprised of 2101 South Korean students in schools. Bullying victimization and perpetration were found to be significant risk factors for negative physical health outcomes, such as asthma, rhinitis, and obesity.

Jiang et al. (2019) explore whether depressive symptoms mediates the association between subtypes of peer victimization and self-harm behaviors among Chinese children affected by parental HIV. Sample for their study comprises 521 students in mainland China, 6-12 years of age at baseline. The study reported that verbal form of peer victimization, but not physical or relational form of peer victimization, increased self-harm behavior risk over a 24month period. The association between verbal victimization and self-harm behaviors was also found to be mediated by depressive symptoms.

Krygsman and Vaillancourt (2019) explore whether gender non-normative aggression (e.g., overt aggression in girls) and high school transition buffered the association between peer victimization and depression in late childhood and adolescence. Sample for the study comprises 464 youths, ages 11-16 years. Overt aggression not only was found to be associated with depression but also moderated the link between peer victimization and depression. For highly aggressive girls, peer victimization was associated 
with later depression when considering prior symptoms. Relational aggression was not found to buffer the link between peer victimization and depression for both genders.

Lebrun-Harris et al. (2019) explore the prevalence of bullying victimization and perpetration, as reported by parents, and health-related factors that are associated with bullying. The study consists of a nationally representative sample of U.S. children and adolescents, ages 6-17 years. Results indicated that $22.7 \%$ of children and adolescents were bullied and $6.4 \%$ bullied others, and the rate of victimization was slightly higher among 6-11-year old children than among 12-17-year old children. In terms of the rate of bullying perpetration, children comprised $7.2 \%$, while adolescents comprised $5.6 \%$. Several health conditions and health services factors were significantly related to bullying victimization or perpetration.

Livingston et al. (2019) explore the associations among bullying, negative affect, and alcohol, cigarette, electroniccigarette, and marijuana use. The study includes a community sample of 204 U.S. adolescents, ages 13-16 years. Their findings indicated that victimization was related to higher than average levels of sadness, anger, and cigarette use. However, victimization was not significantly related to alcohol, electronic-cigarette, or marijuana use. Perpetration did not predict negative affect or alcohol, cigarette, electronic-cigarette, and marijuana use.

Ostrov et al. (2019) study consists of two short-term longitudinal studies, which explore relational aggression and relational bullying as differential predictors of relational victimization and social maladjustment. The first study reported that relational aggression but not relational bullying was a predictor of relational victimization, and the second study found that relational bullying was negatively related to social maladjustment.

Prino et al. (2019) explore whether alexithymia mediates the association between bullying victimization and internalizing and externalizing problems. Sample for the study consists of 1092 4th to 6th grade students and their teachers in Italy $(N=67)$. Findings indicated that verbal, physical and social bullying victimization were significantly associated with internalizing problems, externalizing problems, and alexithymic symptoms. The study also found that alexithymia partially mediated the effect of verbal, physical, and social bullying victimization on both internalizing and externalizing problems.

Shaw et al. (2019) explores factors that are related to students telling an adult at school about being victimized by peers, and the relationship between peer victimization and internalizing problems a year after seeking help from an adult at school. Their study is comprised of a sample of 7 to 9 -year-old Australian students in 12 schools. They found that peer victimization and internalizing problems at Time 2
(T2) among students victimized at Time 1 (T1) were related to telling an adult at $\mathrm{T} 1$, and these relationships were moderated by the severity of peer victimization at T1. For students who reported severe victimization at $\mathrm{T} 1$, speaking with a school staff member was positively related to increased risk of victimization at $\mathrm{T} 2$, but these students reported fewer internalizing problems relative to their peers who did not tell a staff member.

Waasdorp et al. (2019) explore risk factors associated with bullying and victimization while considering several health conditions and health-related behaviors. Their study includes a sample of 64,670 youths from 107 middle and high schools in Maryland. Their results suggest that youth who are obese had higher likelihood of being a victim or bully/victim. Youth with asthma had higher odds of being victimized, both face-to-face and online, and were more likely to be identified as cyberbully/victims. Youth with sleep difficulties were also more likely to be involved in bullying, be identified as a victim or bully/victim, both faceto-face and cyber. These youth also reported higher likelihood of bullying others. On the contrary, healthy food consumption was found to be related to lower odds of bullying perpetration, and physical activity negatively predicted being a bully-victim.

Yubero et al. (2019) explore bullying behaviors in residential childcare context in Spain. More specifically, they examine the association between bullying and psychological distress. Their study utilizes a sample of 56 youths in residential childcare facilities and 1481 youths residing with at least one biological parent. Those in residential childcare reported higher levels of bullying perpetration and victimization relative to their peers who were living with a biological parent. Moreover, living in residential childcare facilities was also found to be positively associated with psychological distress and bullying perpetration.

The study findings included in this Special Issue indicates that experiences in bullying and peer victimization are significantly relevant to children and adolescent's physical, emotional, behavioral, and mental health. Countries and regions of these studies include Australia, Canada, China, Finland, Germany, Italy, the Netherlands, South Korea, Spain, Taiwan, Turkey, and the U.S. Each study presented in this Special Issue provides a platform for researchers, school personnel, practitioners, and health practitioners to hold a dialogue on ways in which bullying and associated health outcomes can be effectively addressed.

We hope that scholars all over the world will continue to expand our understanding of bullying and associated health outcomes. Children and adolescent health is a global public health priority, and the best way to ensure that each and every child grows up healthy requires finding ways to provide safe family, school, and neighborhood environments. 


\section{Compliance with Ethical Standards}

Conflict of Interest The authors declare that they have no conflict of interest.

Ethical Approval Disclosure of statement about research involving human participants and/or animals and informed consent were not required for this manuscript.

Publisher's note: Springer Nature remains neutral with regard to jurisdictional claims in published maps and institutional affiliations.

\section{References}

Arseneault, L., Bowes, L., \& Shakoor, S. (2010). Bullying victimization in youths and mental health problems: 'much ado about nothing'? Psychological Medicine, 40, 717-729.

Attar-Schwartz, S., Mishna, F., \& Khoury-Kassabri, M. (2019). The role of classmates' social support, peer victimization and gender in externalizing and internalizing behaviors among Canadian youth. Journal of Child and Family Studies, 28.

Baier, D., Hong, J. S., Kliem, S., \& Bergmann, C. (2019). Consequences of bullying on adolescents' mental health in Germany: comparing face-to-face bullying and cyberbullying. Journal of Child and Family Studies, 28.

Baldry, A. C., Sorrentino, A., \& Farrington, D. P. (2019). Posttraumatic stress symptoms among Italian preadolescents involved in school and cyber bullying and victimization. Journal of Child and Family Studies, 28.

Cooper, C. L., Hoel, H., \& Faragher, B. (2004). Bullying is detrimental to health, but not necessarily equally damaging. British Journal of Guidance \& Counselling, 32, 367-387.

Copeland, W. E., Bulik, C. M., Zucker, N., Wolke, D., Lereya, S. T., \& Costello, E. J. (2015). Does childhood bullying predict eating disorder symptoms? A prospective, longitudinal analysis. International Journal of Eating Disorders, 48, 1141-1149.

Davis, J. P., Merrin, G. J., Ingram, K. M., Espelage, D. L., Valido, A., \& El Sheikh, A. J. (2019). Examining pathways between bully victimization, depression, \& school belonging among early adolescents. Journal of Child and Family Studies, 28.

deLara, E. W. (2009). Consequences of childhood bullying on mental health and relationships for young adults. Journal of Child and Family Studies, 28.

DePaolis, K. J., \& Williford, A. (2019). Pathways from cyberbullying victimization to negative health outcomes among elementary school students: a longitudinal investigation. Journal of Child and Family Studies, 28.

Duru, E., Balkis, M., \& Turkdogan, T. (2019). Relational violence, social support, self-esteem, depression and anxiety: a moderated mediation model. Journal of Child and Family Studies, 28.

Evans, C. B. R., Smokowski, P. R., Rose, R. A., Mercado, M. C., \& Marshall, K. J. (2019). Cumulative bullying experiences, adolescent behavioral and mental health, and academic achievement: an integrative model of perpetration, victimization, and bystander behavior. Journal of Child and Family Studies, 28.

Fogleman, N. D., Slaughter, K. E., Rosen, P. J., Leadberry, K. D., \& Walerius, D. M. (2019). Emotion regulation accounts for the relation between ADHD and peer victimization. Journal of Child and Family Studies, 28.

Griffiths, L. J., Wolke, D., Page, A. S., \& Horwood, J. P., ALSPAC Study Team. (2006). Obesity and bullying: different effects for boys and girls. Archives of Disease in Childhood, 91, 121-125.
Hadjikakou, K., \& Panayiotis, P. (2012). Bullying and cyberbullying and deaf and hard of hearing children: a review of the literature. The International Journal on Mental Health and Deafness, 2, 18-32.

Hatchel, T., Ingram, K. M., Mintz, S., Hartley, C., Valido, A., Espelage, D. L., \& Wyman, P. (2019). Predictors of suicidal ideation and attempts among LGBTQ adolescents: the roles of helpseeking beliefs, peer victimization, depressive symptoms, and drug use. Journal of Child and Family Studies, 28.

Hatchel, T., Subrahmanyam, K., \& Negriff, S. (2019). Adolescent peer victimization and internalizing symptoms during emerging adulthood: The role of online and offline social support. Journal of Child and Family Studies, 28.

Hatchel, T., Valido, A., De Pedro, K. T., Huang, Y., \& Espelage, D. L. (2019). Minority stress among transgender adolescents: The role of peer victimization, school belonging, and ethnicity. Journal of Child and Family Studies, 28.

Gibson-Young, L., Martinasek, M. P., Clutter, M., \& Forrest, J. (2014). Are students with asthma at increased risk for being a victim of bullying in school or cyberspace? Findings from the 2011 Florida Youth Risk Behavior Survey. Journal of School Health, 84, 429-434.

Herkama, S., Turunen, T., Sandman, N., \& Salmivalli, C. (2019). Sleeping problems partly mediate the association between victimization and depression among youth. Journal of Child and Family Studies, 28.

Holt, M. K., Vivolo-Kantor, A. M., Polanin, J. R., Holland, K. M., DeGue, S., Matjasko, J. L., \& Reid, G. (2015). Bullying and suicidal ideation and behaviors: a meta-analysis. Pediatrics, 135, e496-e509.

Hsieh, Y. P., Wei, H. S., Hwa, H. L., Shen, A. C. T., Feng, J. Y., \& Huang, C. Y. (2019). The effects of peer victimization on children's internet addiction and psychological distress: the moderating roles of emotional and social intelligence. Journal of Child and Family Studies, 28.

Huitsing, G., Lodder, G. M. A., Oldenburg, B., Schacter, H. L., Salmivalli, C., Juvonen, J., \& Veenstra, R. (2019). The healthy context paradox: victims' adjustment during an anti-bullying intervention. Journal of Child and Family Studies, 28.

Jennings, S, Kim, F, and Piquero (2019). An examination of bullying and physical health problems in adolescence among South Korean youth. Journal of Child and Family Studies, 28.

Jiang, Y., Li, X., Zhao, J., \& Zhao, G. (2019). Subtypes of peer victimization, depressive symptoms, and self-harm behaviors among children affected by parental HIV. Journal of Child and Family Studies, 28.

Krygsman, A. L., \& Vaillancourt, T. (2019). Peer victimization and depression symptoms: the moderating role of gender nonnormative aggression and school transition. Journal of Child and Family Studies, 28.

Larson, J. S. (1996). The World Health Organization's definition of health: social versus spiritual health. Social Indicators Research, 38, 181-192.

Lebrun-Harris, L., Sherman, L. J., Limber, S. P., Miller, B. D., \& Edgerton, E. A. (2019). Bullying victimization and perpetration among U.S. children and adolescents: 2016 National Survey of Children's Health. Journal of Child and Family Studies, 28.

Lindsay, S., \& McPherson, A. C. (2012). Experiences of social exclusion and bullying at school among children and youth with cerebral palsy. Disability and Rehabilitation, 34, 101-109.

Livingston, J. A., Derrick, J. L., Wang, W., Testa, M., Nickerson, A. B., Espelage, D. L., \& Miller, K. E. (2019). Proximal association among bullying, mood, and substance use: a daily report study. Journal of Child and Family Studies, 28.

National Academies of Science, Engineering, and Medicine. (2016). Preventing bullying through science, policy, and practice. Washington, DC: The National Academies Press. 
Ostrov, J. M., Kamper-DeMarco, K. E., Blakely-McClure, S. J., Perry, K. J., \& Mutignani, L. (2019). Prospective associations between aggression/bullying and adjustment in preschool: is general aggression different from bullying behavior? Journal of Child and Family Studies, 28.

Prino, L. E., Longobardi, C., Fabris, M. A., Parada, R. R., \& Settanni, M. (2019). Effects of bullying victimization on internalizing and externalizing symptoms: the mediating role of alexithymia. Journal of Child and Family Studies, 28.

Shaw, T., Campbell, M. A., Eastham, J., Runions, K. C., Salmivalli, C., \& Cross, D. (2019). Telling an adult at school about bullying: subsequent victimization and internalizing problems. Journal of Child and Family Studies, 28.

Srabstein, J. C., \& Leventhal, B. L. (2010). Prevention of bullyingrelated morbidity and mortality: a call for public health policies. Bulletin of the World Health Organization, 88, 403-403.
Takizawa, R., Maughan, B., \& Arseneault, L. (2015). Adult health outcomes of childhood bullying victimization: evidence from a five-decade longitudinal British birth cohort. The American Journal of Psychiatry, 171, 777-784.

Waasdorp, T. E., Mehari, K. R., Milam, A. J., \& Bradshaw, C. P. (2019). Health-related risks for involvement in bullying among middle and high school youth. Journal of Child and Family Studies, 28.

Wolke, D., Copeland, W. E., Angold, A., \& Costello, E. J. (2013). Impact of bullying in childhood on adult health, wealth, crime, and social outcomes. Psychological Science, 24, 1958-1970.

Yubero, S., Navarro, R., Maldonado, M. J., Gutierrez-Zomoza, M., Elche, M., \& Larranaga, E. (2019). Bullying and psychological distress in a vulnerable group: youth in residential child care. Journal of Child and Family Studies, 28. 